Article

\title{
Nickel-Doped Ceria Nanoparticles: The Effect of Annealing on Room Temperature Ferromagnetism
}

\author{
Joseph C. Bear ' , Paul D. McNaughter ${ }^{2}$, Paul Southern ${ }^{3}$, Paul O'Brien ${ }^{2,4}$ \\ and Charles W. Dunnill 1,*
}

1 Energy Safety Research Institute (ESRI), College of Engineering, Swansea University, Bay Campus, Fabian Way Swansea SA1 8EN, UK; E-Mail: j.c.bear@swansea.ac.uk

2 School of Chemistry, University of Manchester, Oxford Road, Manchester M13 9PL, UK;

E-Mails: paul.mcnaughter@manchester.ac.uk (P.D.M.); paul.o’brien@manchester.ac.uk (P.O.)

3 UCL Healthcare Biomagnetics Laboratories, Royal Institution of Great Britain, 21 Albemarle Street, London W1S 4BS, UK; E-Mail: p.southern@ucl.ac.uk

4 School of Materials, University of Manchester, Oxford Road, Manchester M13 9PL, UK

* Author to whom correspondence should be addressed; E-Mail: c.dunnill@swansea.ac.uk; Tel.: +44-1792-606244.

Academic Editor: Ramesh K. Guduru

Received: 30 June 2015 / Accepted: 17 August 2015 / Published: 21 August 2015

\begin{abstract}
Nickel-doped cerium dioxide nanoparticles exhibit room temperature ferromagnetism due to high oxygen mobility within the doped $\mathrm{CeO}_{2}$ lattice. $\mathrm{CeO}_{2}$ is an excellent doping matrix as it can lose oxygen whilst retaining its structure. This leads to increased oxygen mobility within the fluorite $\mathrm{CeO}_{2}$ lattice, leading to the formation of $\mathrm{Ce}^{3+}$ and $\mathrm{Ce}^{4+}$ species and hence doped ceria shows a high propensity for numerous catalytic processes. Magnetic ceria are important in several applications from magnetic data storage devices to magnetically recoverable catalysts. We investigate the effect doping nickel into a $\mathrm{CeO}_{2}$ lattice has on the room temperature ferromagnetism in monodisperse cerium dioxide nanoparticles synthesised by the thermal decomposition of cerium(III) and nickel(II) oleate metal organic precursors before and after annealing. The composition of nanoparticles pre- and post-anneal were analysed using: TEM (transmission electron microscopy), XPS (X-ray photoelectron spectroscopy), EDS (energy-dispersive X-ray spectroscopy) and XRD (X-ray diffraction). Optical and magnetic properties were also studied using UV/Visible spectroscopy and SQUID (superconducting interference device) magnetometry respectively.
\end{abstract}

Keywords: ceria; nickel doping; ferromagnetism; catalysis; nanoparticles 


\section{Introduction}

Metal oxide nanoparticles have been an area of intense research and rapid development over the last twenty years, because of interest in utilizing their unique properties afforded to them by their small size. Metal oxide nanoparticles straddle the boundary between bulk materials and molecules and are a major driving force behind cutting-edge technological development [1-5]. Metal oxide nanoparticles have seen successful and widespread use in applications as diverse as: energy materials [6-9], thermochromics [10-12], magnetism [13-15], medicine [16-20], imaging [21-23], communications technology and data storage [24-26], catalysts for organic transformations [27] and superhydrophobic surfaces $[15,28,29]$.

Cerium(IV) oxide (ceria) and metal-doped ceria nanoparticles have been developed for their role in catalysis [30-36]. One of the features that makes ceria attractive for catalysis is its ability to release/uptake oxygen from its lattice without losing its structural integrity [37]. Cerium(IV) oxide has the fluorite structure, in which the oxygen are packed along the same plane. This allows high oxygen mobility through the lattice as the number of oxygen vacancies to increase, with cerium atoms changing oxidation state from $\mathrm{Ce}^{4+}$ to $\mathrm{Ce}^{3+}$ increasing the propensity for redox chemistry. The ability for ceria to readily develop oxygen vacancies is key to its effectiveness as a dopant matrix [38].

Various transition and lanthanide metals have been used to dope ceria to enhance catalytic activity [31,39], performance in solid oxide fuel cells [40] and to develop magnetic properties [41,42]. Transition metals, particularly Mn [43], Fe [44], Co [45] and Ni [46] have all been doped into ceria to affect room temperature ferromagnetism and form dilute magnetic semiconductor oxides. It has been hypothesized by several groups that the room temperature ferromagnetism is due to the creation of oxygen vacancies in the $\mathrm{CeO}_{2}$ lattice. Oxygen vacancies which generate exchange interactions between unpaired electron spins and changes in surface chemical states are both postulated to affect room temperature ferromagnetism [47-49]. Oxygen vacancies also effect the band structure of the host $\mathrm{CeO}_{2}$, often dramatically affecting optical properties [50-52]. Studies involving the doping of non-magnetic elements into $\mathrm{CeO}_{2}$ such as $\mathrm{Ca}^{2+}$ [53] and $\mathrm{Cr}^{3+}$ [48] support this as they also demonstrate room temperature ferromagnetism.

Thurber et al. demonstrated that room temperature ferromagnetism in Ni-doped $\mathrm{CeO}_{2}$ is not due to the formation/coagulation of ferromagnetic nickel within the material [42]. This was determined by the absence of nickel/nickel oxide diffraction peaks in X-ray diffraction pattern (and observations of shifting of the Curie temperature with different Ni doping levels showing doping throughout the material), and the fact that ferromagnetic properties did not increase with high amounts of nickel doping. Pure phase $\mathrm{CeO}_{2}$ and heavily $\mathrm{Ni}$-doped samples did not show ferromagnetism, indicating that a random impurity could be eliminated as the cause of the ferromagnetism as the magnetic moment would be identical throughout the doped/pure phase samples.

In this paper, we present the synthesis of nickel-doped cerium dioxide nanocrystals by the thermal decomposition of metal-oleate complexes in the presence of surfactants at high temperature; a route which has a high success rate in producing large quantities of highly monodisperse nanocrystals. The synthesis of Ni-doped $\mathrm{CeO}_{2}$ via this route has advantages over Fe, Co or $\mathrm{Cr}$ doped $\mathrm{CeO}_{2}$ due to the ease in which the solid precursor, nickel(II) oleate, can be handled and stored for long periods of time in comparison to viscid iron(III) oleate or air-sensitive cobalt(II) oleate. We investigated the effect of 
annealing in air on the composition, crystallinity and room-temperature ferromagnetic properties using superconducting quantum interference device (SQUID) magnetometry. Nanoparticles were characterised using transmission electron microscopy (TEM), X-ray photoelectron spectroscopy (XPS), UV/Visible spectroscopy (UV/Vis), X-ray diffraction (XRD) and energy dispersive X-ray spectroscopy (EDS).

\section{Results and Discussion}

The thermal decomposition of metal-oleate complexes has been shown to be an excellent method for the synthesis of large quantities of monodisperse metal oxide nanoparticles. The method involves the synthesis of the metal-oleate complex by a salt metathesis reaction between the metal chloride and sodium oleate, to give the metal-oleate and sodium chloride. Aside from the formation of sodium chloride, phase transfer in the two-phase solvent system (a mixture of water, ethanol and $n$-hexane) provides a major driving force.

Once isolated, cerium(III) and nickel(II) oleate complexes are gold and bright green waxy solids respectively, and are easier to manipulate than their iron(III) or cobalt(II) counterparts due to their higher viscosity. Ni-doped ceria nanoparticles were synthesised by decomposing different ratios of cerium(III) and nickel(II) oleate in the presence of a surfactant (oleic acid) and a high boiling point solvent (1-octadecene) at $320^{\circ} \mathrm{C}$. The ratios for different nickel doping levels are given in Table 1 .

Table 1. Samples synthesized and used in this study with the amounts of starting reagents listed.

\begin{tabular}{cccc}
\hline Sample & Ce[oleate $]_{3}$ used $/ \mathbf{g}, \mathbf{m m o l}$ & $\mathbf{~ N i [ o l e a t e}]_{2}$ used $/ \mathbf{g}, \mathbf{m m o l}$ & Sample Number \\
\hline $\mathrm{CeO}_{2}$ & $4,4.06$ & 0,0 & 1 \\
$\mathrm{NiO}$ & 0,0 & $2.52,4.06$ & 2 \\
$50 \% \mathrm{Ni}-\mathrm{CeO}_{2}$ & $2,2.03$ & $0.662,2.03$ & 3 \\
$10 \% \mathrm{Ni}-\mathrm{CeO}_{2}$ & $3.59,3.65$ & $0.25,0.406$ & 4 \\
$8 \% \mathrm{Ni}-\mathrm{CeO}_{2}$ & $3.62,3.68$ & $0.2,0.325$ & 5 \\
$5 \% \mathrm{Ni}-\mathrm{CeO}_{2}$ & $3.86,3.8$ & $0.125,0.203$ & 6 \\
$4 \% \mathrm{Ni}-\mathrm{CeO}_{2}$ & $3.84,3.9$ & $0.1,0.162$ & 7 \\
$3 \% \mathrm{Ni}-\mathrm{CeO}_{2}$ & $3.88,3.94$ & $0.075,0.122$ & 8 \\
$2 \% \mathrm{Ni}-\mathrm{CeO}_{2}$ & $3.92,3.98$ & $0.05,0.08$ & 9 \\
$1 \% \mathrm{Ni}-\mathrm{CeO}_{2}$ & $4.02,3.96$ & $0.025,0.0406$ & 10 \\
\hline
\end{tabular}

Post-decomposition, nanoparticles were isolated as black sticky residues, several ethanol washes/centrifuge cycles were used to remove excess oleate-type species and 1-octadecene. Once washed, the nanoparticles were readily dispersible in organic solvents. At this stage, the samples were divided in two, with one half kept for analysis and the other half annealed at $450{ }^{\circ} \mathrm{C}$ in air for $12 \mathrm{~h}$. The annealed powders were free flowing and different in color, with the most marked example being Sample 1 changing from dark brown to yellow. The composition of nanoparticles pre- and post-anneal were characterised using: TEM, XPS, EDS and XRD. Their optical properties were also analysed using UV/Visible spectroscopy.

TEM analysis demonstrated the effectiveness of the metal-oleate decomposition method for the synthesis of large quantities of monodisperse nanoparticles (Figure 1). 



Figure 1. TEM images of pre- and post annealed samples. (a) Sample $1\left(\mathrm{CeO}_{2}\right.$ nanoparticles); (b) Sample 1 (annealed); (c) Sample 2 (NiO nanoparticles); (d) Sample 2 (annealed) showing a $d$-spacing of $0.238 \mathrm{~nm}$ assigned to the $<111>$ plane of $\mathrm{NiO}$; (e) Sample $3\left(50 \% \mathrm{Ni}-\mathrm{CeO}_{2}\right)$; (f) Sample 7 (4\% Ni-CeO $)$; (g) Sample 9 (2\% Ni-CeO2, annealed) and (h) Sample 5 (8\% $\mathrm{Ni}-\mathrm{CeO}_{2}$, annealed) showing showing a $d$-spacing of $0.238 \mathrm{~nm}$ assigned to the $<111>$ plane of $\mathrm{CeO}_{2}$.

Sample $1\left(\mathrm{CeO}_{2}\right)$ showed spherical nanoparticles of $1.83 \pm 0.47 \mathrm{~nm}$ in diameter with very little shape anisotropy (on annealing $7.41 \pm 2.1 \mathrm{~nm}$ ). However, on nickel doping, shape anisotropy increased, as did overall sample polydispersity. Sample 5 gave a mean size of $2.63 \mathrm{~nm}$ with a standard deviation of 1.18 $\mathrm{nm}$ (Figure 1). TEM and therefore EDS analysis was exacting due to the amount of carbon contamination on the TEM grids from the blanket coverage of oleic acid on nanoparticle surfaces/excess oleic acid in solution. Once annealed, high resolution images were taken, as was a more accurate EDS analysis with little carbon contamination (Figure 2).

On annealing, nanoparticle size increased. Sample 5 increased from $2.63 \pm 1.18 \mathrm{~nm}$ to $7.11 \pm 3.37 \mathrm{~nm}$. Annealing had a particularly marked effect on Sample $2(\mathrm{NiO})$ which showed a very large increase in particle size $(3.77 \pm 0.90 \mathrm{~nm}$ to $21.49 \pm 5.28 \mathrm{~nm})$ and crystallinity, supported by peak narrowing in its XRD pattern (Figure $4 \mathrm{j}$ ). 
Characterisation by TEM was supported by compositional analysis by XPS and EDS spectroscopy. Results from composition analysis by quantitative XPS are fully summarised in Table 2. EDS spectra were effective in identifying the elements present in pre-annealed samples, although a quantitative comparison of compositions was achieved by analysing XPS spectra.

EDS spectra showed the presence of $\mathrm{Ni}, \mathrm{Ce}$ and $\mathrm{O}$ in the pre-annealed samples, but the high levels of surfactants present (oleic acid) introduced increased background interference. As evidenced in Figure 2a, $\mathrm{c}$ and $\mathrm{d}$, this was solved by examining the annealed samples, as annealing entirely removed this background.

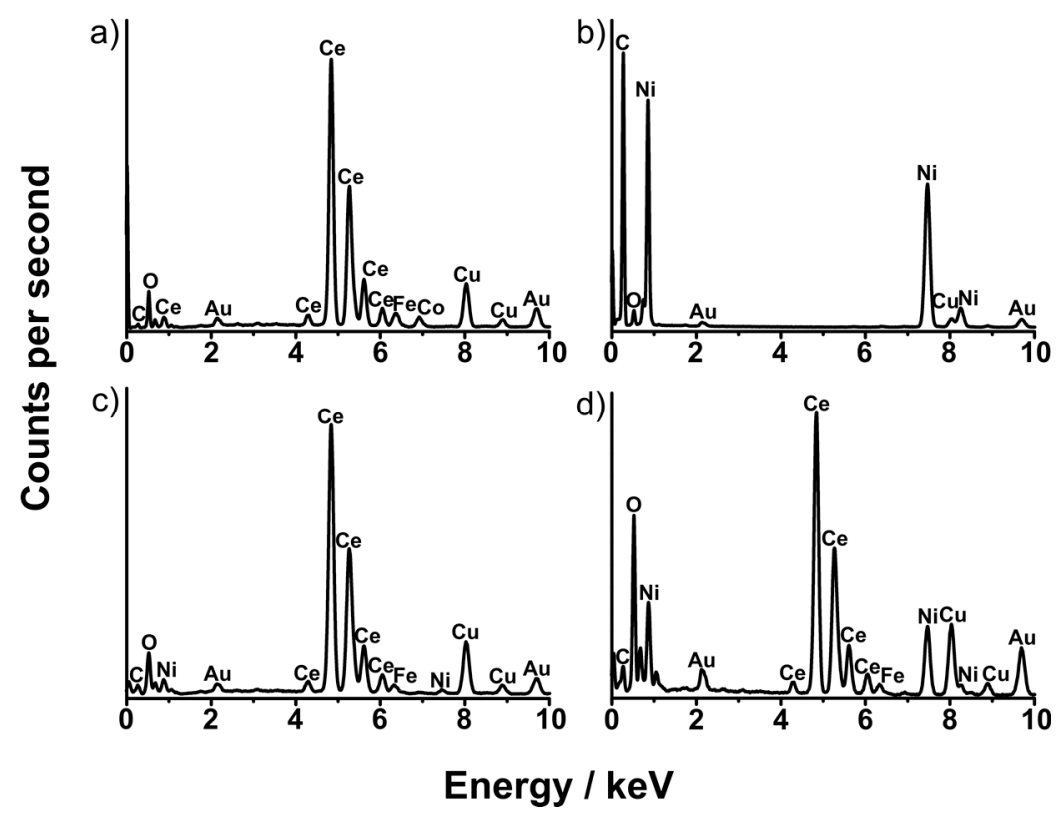

Figure 2. Exemplar EDS spectra of non-annealed and annealed samples. (a) $\mathrm{CeO}_{2}$ nanoparticles (annealed); (b) NiO nanoparticles (non-annealed), showing the high carbon content from the nanoparticle ligands; (c) $\mathrm{Ni}-\mathrm{CeO}_{2}$ (8\% doping, Sample 5, annealed) and (d) $\mathrm{Ni}-\mathrm{CeO}_{2}$ (2\% doping, Sample 9, annealed).

XPS was used to determine the presence and composition of elements in the doped and undoped samples. Quantitative XPS results are listed in Table 2, with all samples showing the desired ratios of Ce to $\mathrm{Ni}$ in accordance with the amount of precursors used (Table 1). The survey scan revealed a degree of sodium in the samples and is a possible contaminant derived from sodium oleate used in the precursor synthesis.

High resolution Ce $3 \mathrm{~d}$ XPS spectra showed spectra typical of a $\mathrm{Ce}(\mathrm{IV})$ species, specifically for cerium(IV) oxide $\left(\mathrm{CeO}_{2}\right)$ [54-56]. $\mathrm{Ce}^{4+}$ exhibits six peaks comprised of 3 pin-orbit doublets due to different $\mathrm{Ce} 4 \mathrm{f}$ occupancies post-excitation. The peak positions and doublet separation $(\Delta)$ for Sample 3 are as follows: peak positions: $880.6,886.5,896.3,899.2,905.8$ and $914.7 \mathrm{eV}, \Delta=18.5 \mathrm{eV}$ ).

One of the difficulties in analysing Ni-doped cerium dioxide is that the most intense signals for $\mathrm{Ni}$ and $\mathrm{Ce}(\mathrm{Ni} 2 \mathrm{p}$ and $\mathrm{Ce} 3 \mathrm{~d}$ ) have a degree of overlap in Figure $3 \mathrm{c}$. Figure $3 \mathrm{~d}$ is the $\mathrm{Ni} 2 \mathrm{p}$ high resolution scan from Sample 2 (pure phase $\mathrm{NiO}$ ) and it is clear that a substantial portion of the $\mathrm{Ni} 2 \mathrm{p}_{1 / 2}$ is masked by the Ce $3 \mathrm{~d}_{3 / 2}$ peak. The full Ni2p scan is evident in Figure $3 \mathrm{~d}$, which is indicative of NiO (peak positions: $853.5,855.2,860.7,872.0$ and $879.3 \mathrm{eV}, \Delta=18.5 \mathrm{eV})[54,57]$. 

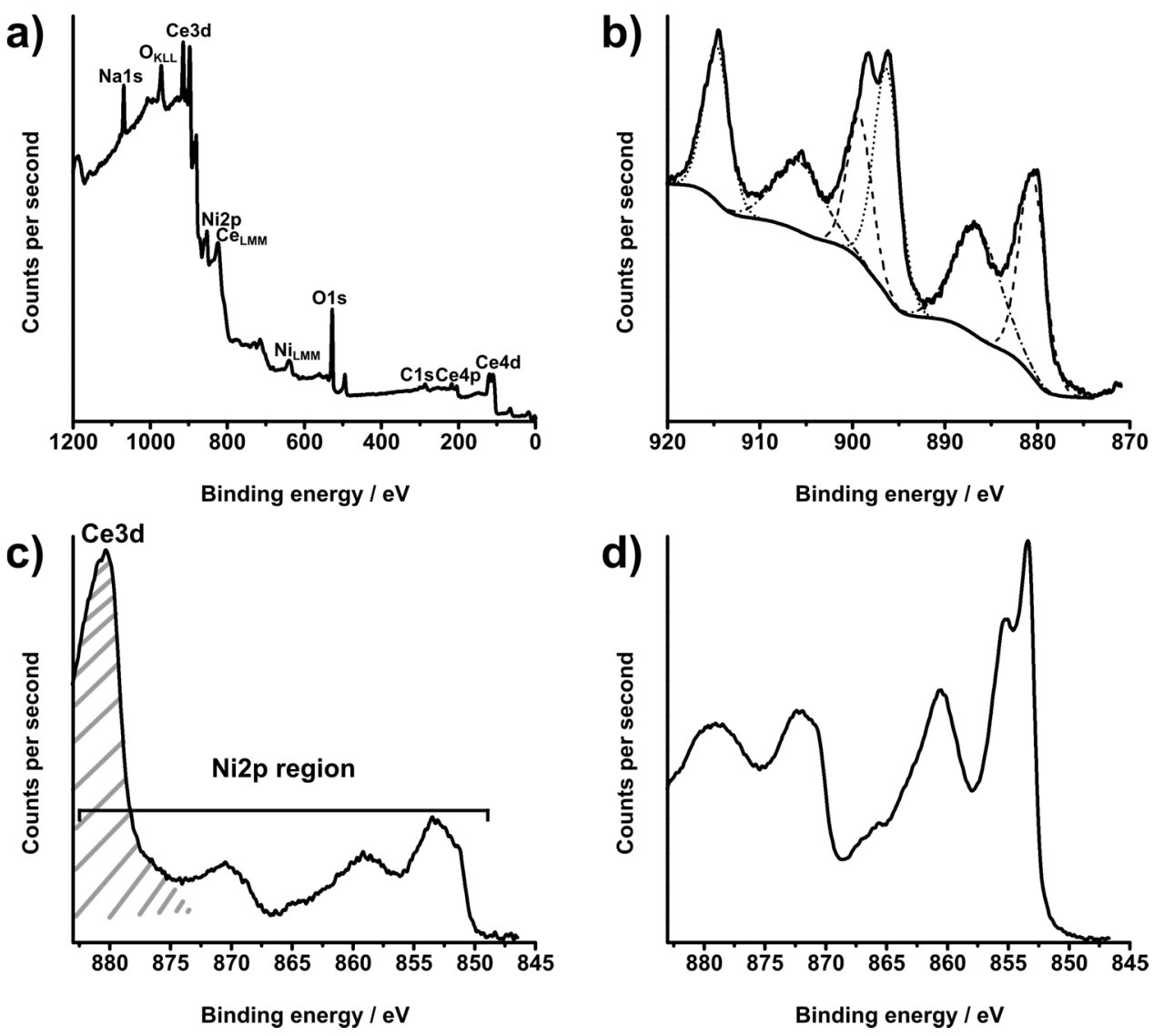

Figure 3. (a) XPS survey scan of Sample $3\left(50 \% \mathrm{Ni}-\mathrm{CeO}_{2}\right)$ showing elements present; (b) Fitted Ce $3 \mathrm{~d}$ high resolution XPS spectrum showing the 3 doublets that are indicative of $\mathrm{Ce}(\mathrm{IV})$ and indeed $\mathrm{CeO}_{2}$; (c) $\mathrm{Ni} 2 \mathrm{p}$ region of Sample 3, showing the overlapping Ce 3d region which masks the $\mathrm{Ni} 2 \mathrm{p}_{1 / 2}$ region; (d) is a high resolution scan of the $\mathrm{Ni} 2 \mathrm{p}$ region in Sample 2 (pure phase $\mathrm{NiO}$ ).

Table 2. Nanoparticle compositional analysis by quantitative XPS spectroscopy.

\begin{tabular}{cccc}
\hline Sample & $\begin{array}{c}\text { Ce Composition by } \\
\text { XPS/at.\% }\end{array}$ & $\begin{array}{c}\text { O Composition by } \\
\text { XPS/at.\% }\end{array}$ & $\begin{array}{c}\text { Ni Composition by } \\
\text { XPS/at.\% }\end{array}$ \\
\hline 1 & 37.79 & 62.21 & - \\
2 & - & 49.52 & 50.48 \\
3 & 22.02 & 54.57 & 23.40 \\
4 & 36.51 & 59.64 & 3.86 \\
5 & 32.72 & 64.80 & 2.48 \\
6 & 34.26 & 63.88 & 1.86 \\
7 & 32.92 & 65.81 & 1.27 \\
8 & 36.98 & 62.13 & 0.90 \\
9 & 37.95 & 61.47 & 0.58 \\
10 & 33.43 & 66.32 & 0.25 \\
\hline
\end{tabular}

XRD patterns were easily obtained on powder samples post-annealing and demonstrated the propensity of the ceria lattice to receive metal ion dopants without significant structural re-arrangement or collapse (Figure 4). All patterns (bar NiO, Sample 2) were shown to exhibit the halite structure of cerium(IV) oxide (COD: 4343161) [50,58], with Sample 2 showing the cubic structure of NiO (COD: 1010093). 


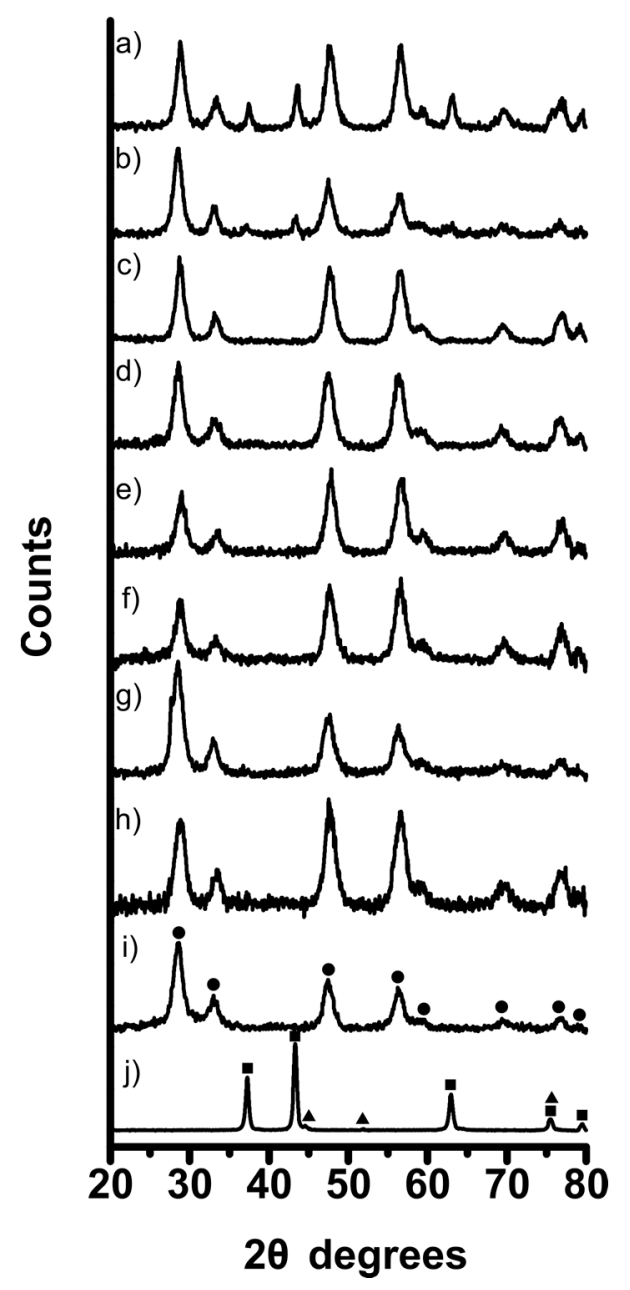

Figure 4. Powder X-ray diffraction patterns of: (a) Sample $3\left(50 \% \mathrm{Ni}-\mathrm{CeO}_{2}\right.$, annealed); (b) Sample 4 (10\% Ni-CeO2, annealed); (c) Sample 5 ( $8 \% \mathrm{Ni}-\mathrm{CeO}_{2}$, annealed); (d) Sample 6 ( $5 \% \mathrm{Ni}-\mathrm{CeO}_{2}$, annealed); (e) Sample 7 (4\% Ni-CeO 2 , annealed); (f) Sample 8 (3\% Ni-CeO annealed); (g) Sample 9 (2\% Ni-CeO 2 , annealed); (h) Sample 10 (1\% Ni-CeO2, annealed); (i) Sample $1\left(\mathrm{CeO}_{2}\right.$, annealed) and (j) Sample $2(\mathrm{NiO}$, annealed). Circles represent the diffraction peaks from the standard pattern of $\mathrm{CeO}_{2}$ (COD: 4343161), squares standard data from $\mathrm{NiO}$ (COD: 1010093) and triangles standard data from Ni metal (COD: 1512526).

When nickel doping was increased beyond $8 \%$, Figure $3 b, c$ shows the emergence of the nickel oxide pattern. In Sample 3 (1:1 molar ratio of cerium and nickel precursors), it is evident that a mixed phase system exists, supported by TEM micrographs which show two distinct nanoparticle populations. On annealing, Sample $2(\mathrm{NiO})$ exhibited narrowed peaks compared to those of the non-annealed sample (Figure S1) consistent with nanoparticle sintering and increased crystallised size seen by TEM micrographs (Figure 2c,d). The diffraction pattern for Sample 2 also revealed that even after annealing, the $\mathrm{NiO}$ was not phase-pure; indeed there was a degree of Ni present as shown by reflections at $44.7^{\circ}$ and $51.7^{\circ}$ assigned as the $<111>$ and $<200>$ of Ni metal (COD: 1512526). However, this was not seen by high resolution Ni2p XPS spectra of Sample 2, which showed solely NiO. This is indirect evidence of a Ni/NiO core/shell type system as XPS is surface sensitive, whereas XRD analyses the entire sample.

As expected, the presence of Ni metal decreases when comparing the non-annealed and annealed states in sample 2 (Figure S1).XRD patterns were further analysed for unit cell parameter and unit cell 
volume (Table S1) using QualX software with standard data taken from the Crystallography Open Database (COD). However, there was little correlation between the cell parameter values or the unit cell volumes with nickel doping. Reports have suggested that cell parameter decreases with nickel doping due to the smaller size of $\mathrm{Ce}^{3+}$ and $\mathrm{Ce}^{4+}$ compared to $\mathrm{Ni}, \mathrm{Ni}^{+}$or $\mathrm{Ni}^{2+}$ [42], or that nanoscale effects overtake this, and an expansion in unit cell parameters is reported with decreasing nanoparticle size due to $\mathrm{Ce}^{4+}$ replacement with smaller $\mathrm{Ce}^{3+}[59-61]$.

One of the marked effects of introducing oxygen vacancies into $\mathrm{CeO}_{2}$ by transition metal doping is the alteration of the band structure. This can be seen using UV/visible spectroscopy, specifically diffuse reflectance spectroscopy on powder samples. A sample of the results are summarised in Figure 5.

Figure 5 shows the change in diffuse reflectance optical spectra with increased nickel doping. Using these data, it is possible to determine the optical band-gap of the samples after applying the Kubelka-Munk function (Equation (1)):

$$
F(R)=\left(\frac{(1-R)}{2 R}\right)^{2}
$$

The band gap of Sample 1 (pure $\mathrm{CeO}_{2}$ ) was found to be $3.81 \mathrm{eV}$, in agreement with the literature value of $3.78 \mathrm{eV}$ for cerium(IV) oxide [62]. With increasing nickel doping, the band gap increases to $3.7,3.5,3.81 \mathrm{eV}$ and $3.93 \mathrm{eV}$ for $1 \%, 2 \%, 3 \%$ and $8 \%$ doping respectively. This is consistent with reports that show that ceria nanoparticles of decreasing size show an increase in bad gap energy [59]. TEM image analysis post annealing showed that particle size decreased slightly on Ni-doping, with the exception of sample 2 (pure $\mathrm{NiO}$ ) which was dramatically different to any of the samples containing cerium. Thurber et al. reported changes in band gap energy of nickel doped ceria systems as a combination of particle size effects and structural changes brought about by interstitial Ni incorporation, even at the $1 \%$ level [42]. The authors also show a decrease in the band gap up to $x \leq 0.04\left(\mathrm{Ce}_{1-x} \mathrm{Ni}_{x} \mathrm{O}_{2}\right)$ but an increase thereafter, and correlated their findings with lattice strain induced by nickel doping. Our samples did exhibit this trend, but only up to $x \leq 0.02$ after which band gap energy values increased, possibly due to smaller particle sizes obtained from our syntheses.

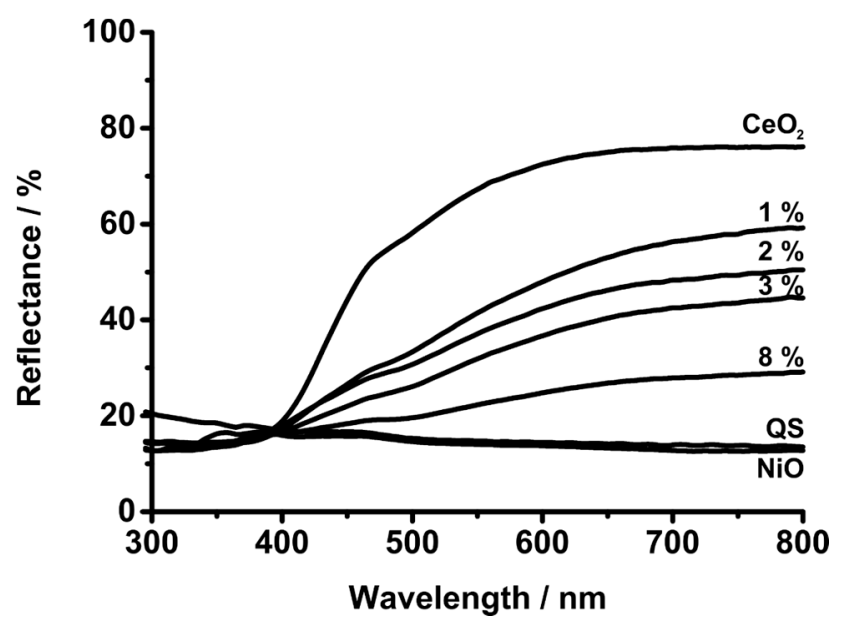

Figure 5. Diffuse-reflectance spectra of nickel-doped $\mathrm{CeO}_{2}$ samples, with reflectance intensity decreasing markedly with increased nickel doping. "QS" is the reflectance spectrum of blank quartz slides. 
Along with changes in the optical properties common in materials of interest in spintronics, the magnetic properties of the $\mathrm{Ni}$-doped $\mathrm{CeO}_{2}$ samples were investigated using SQUID magnetometry (Figure 6). Both pre- and post-annealed $\mathrm{NiO}$ samples (Sample 2) have a coercive field that increase from 14 Oe to 70 Oe post-annealing. The annealing process also impacts the saturation magnetisation with a $17 \%$ increase in saturation post-annealing, commensurate with the increase in crystallinity and particle size.
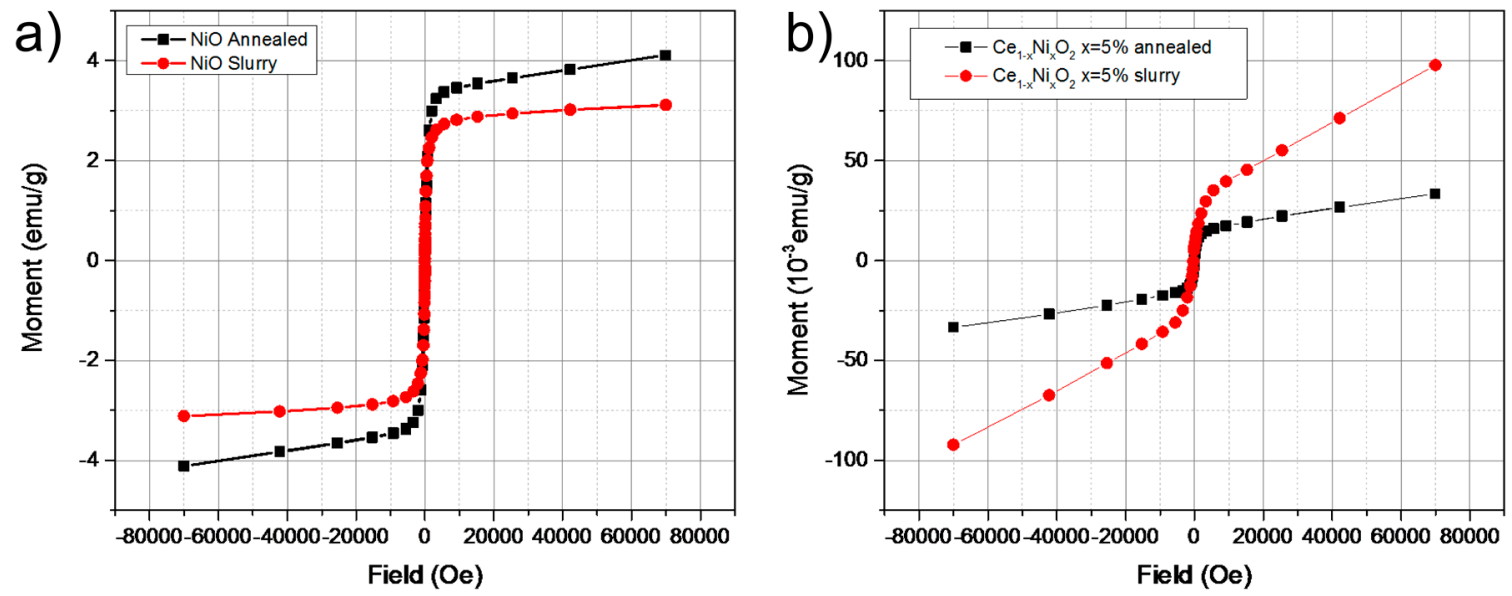

Figure 6. Magnetic hysteresis curves at $300 \mathrm{~K}$ for: (a) $\mathrm{NiO}$ annealed and non-annealed "slurry" samples (Sample 2) and (b) 5\% $\mathrm{Ni}_{-} \mathrm{CeO}_{2}$ (Sample 6). Magnetic saturation values were calculated by removing the high field linear component $(\chi \cdot H)$ from the data.

It is noteworthy that the non-annealed $\mathrm{CeO}_{2}$ sample (Sample 1) showed no magnetism at room temperature, with the annealed sample giving a weak magnetic moment of $1.9 \times 10^{-3} \mathrm{emu} / \mathrm{g}$. Sample 6 , $5 \% \mathrm{Ni}-\mathrm{CeO}_{2}$, showed weak ferromagnetic behaviour, however there was an absence of a coercive field in both annealed and non-annealed samples, presumably due to the small size of the nanoparticles, and the absence of ripening in the doped samples compared with $\mathrm{NiO}$ (Sample 2). Curiously there is however a decrease in the magnetic saturation post-annealing, which is contrary to expectations, however previous studies [42] noted a linear increase of ferromagnetic moment in dopant concentrations below 4\%, with a dramatic decrease thereafter. Therefore, annealing in the case of Sample 6 could be detrimental to the overall moment due to increased crystallinity of the annealed product.

\section{Experimental Section}

\subsection{Materials}

Cerium(III) chloride (purum p.a., $\geq 98.0 \%$ ), nickel(II) chloride hexahydrate (ReagentPlus), 1-octadecene (90\%) oleic acid (90\% technical grade) and sodium oleate ( $\geq 82 \%$ fatty acids) were purchased from Sigma-Aldrich Ltd., UK Ethanol ( $\geq 99.8 \%(\mathrm{GC}))$ and $n$-hexane (Laboratory Reagent, $\geq 95 \%)$ were purchased from VWR limited, UK. UHQ deionized water with a resistivity of not less than 18.2 $\mathrm{M} \Omega \cdot \mathrm{cm}^{-1}$ (Millipore, UK) was used for aqueous solutions. 


\subsection{Methods}

Metal-oleate syntheses: Nickel(II) and cerium(III) oleate complexes were synthesized according to a modified procedure by Park et al. [63]. Briefly, nickel(II) chloride hexahydrate (7.13 g, $30 \mathrm{mmol}$ ) was dissolved in deionized water $(60 \mathrm{~mL})$ and added to a $250 \mathrm{~mL}$ three-necked flask fitted with a condenser and charged with sodium oleate $(18.23 \mathrm{~g}, 60 \mathrm{mmol}), n$-hexane $(105 \mathrm{~mL})$, deionized water $(45 \mathrm{~mL})$ and ethanol $(60 \mathrm{~mL})$. The mixture was refluxed under stirring $\left(\sim 70^{\circ} \mathrm{C}\right)$ for $4 \mathrm{~h}$, giving a dark green suspension in hexane. On cooling, the organic (hexane) layer was isolated and washed with deionized water $(2 \times 100 \mathrm{~mL})$ and evaporated in vacuo to give solid green nickel(II) oleate.

Cerium(III) oleate was synthesized using the method above, with cerium(III) chloride heptahydrate (11.2 g, $30 \mathrm{mmol})$ and 3 equivalents of sodium oleate $(27.4 \mathrm{~g}, 90 \mathrm{mmol})$ used to give cerium(III) oleate as a waxy solid.

Nanoparticle synthesis: Cerium(III) oleate, nickel(II) oleate or a mixture of both (see Table 1) was added to a three-necked $250 \mathrm{~mL}$ flask containing oleic acid $(0.64 \mathrm{~mL}, 2 \mathrm{mmol})$ and 1-octadecene $(30 \mathrm{~mL})$. The mixture was then heated to $320{ }^{\circ} \mathrm{C}$ at a constant rate of $3.3^{\circ} \mathrm{C} \cdot \mathrm{min}^{-1}$ under stirring and kept at $320^{\circ} \mathrm{C}$ for $1 \mathrm{~h}$, developing a vigorous reflux. On cooling, the black suspension was subjected to several ethanol washings/centrifuge cycles $(10 \mathrm{~min}$ at $3000 \times \mathrm{g})$ until a black solid was isolated.

Half the product was then placed into a ceramic crucible before being annealed in air for $12 \mathrm{~h}$ at $450{ }^{\circ} \mathrm{C}$ at a heating rate of $10{ }^{\circ} \mathrm{C} \cdot \mathrm{min}^{-1}$, yielding free flowing powders free of ligands.

The remainder of the product was re-dispersed in $n$-hexane ( $c$. $20 \mathrm{~mL}$ ) giving a colloidally stable black dispersion.

\subsection{Instrumentation}

TEM images were recorded using a FEI Tecnai $\mathrm{G} 220$ with a $\mathrm{LaB}_{6}$ source at an acceleration voltage of $200 \mathrm{kV}$. EDS spectra were taken with an Oxford XMax 80 TLE detector running AZTEC software. UV-Vis absorption spectra were recorded using a Shimadzu UV-1800 UV/Vis spectrometer (Japan) in the wavelength range $200-800 \mathrm{~nm}$. X-ray photoelectron spectra (XPS) were recorded on a Kratos Axis Supra instrument (Kratos Analytical, Manchester, UK) using a monochromated Al Ka source. All spectra were recorded using a charge neutralizer to limit differential charging and subsequently calibrated to the main $\mathrm{C}_{x} \mathrm{H}_{y}$ carbon peak at a binding energy of $284.8 \mathrm{eV}$. Survey scans were recorded at a pass energy of $160 \mathrm{eV}$ and high resolution data at a pass energy of $20 \mathrm{eV}$. Data was fitted using CASA XPS with Shirley backgrounds. XRD diffraction patterns were acquired using a Bruker D8 Advance diffractometer (Germany), using a $\mathrm{Cu} K \alpha$ source $(\lambda=0.154018 \mathrm{~nm})$ with a Gobel mirror optic and Soller slits on the detector side. Scans were acquired at a grazing incidence of $3^{\circ}$ over a $2 \theta$ range of $20^{\circ}-80^{\circ}$ with $0.05^{\circ}$ steps and $3 \mathrm{~s}$ per step. Samples for magnetometery were prepared in polycarbonate sample holders and weighed using a 6 d.p. microbalance before mounting them in a rigid brass tube specifically designed for SQUID magnetometry measurements. A Quantum Design MPMS SQUID-VSM (San Diego, CA, USA) was used to measure $\mathrm{M} v$. $\mathrm{H}$ curves at room temperature $(300 \mathrm{~K})$ with a field range of $\pm 7 \mathrm{~T}$. 


\section{Conclusions}

$\mathrm{Ni}-\mathrm{CeO}_{2}$ nanoparticles were successfully synthesised using the thermal decomposition of metal-oleate precursors. A portion of the obtained nanoparticles were annealed at $450{ }^{\circ} \mathrm{C}$ leading to some sintering (in the case of $\mathrm{NiO}$ ) and increased crystallinity. Nanoparticle structure and composition were characterised using: TEM, XPS, EDS and XRD, giving expected levels of nickel doping and structural deviation. Optical properties were analysed using reflectance spectroscopy, with even low levels of Ni doping (ca. 1\%) having a marked effect on overall reflectance. SQUID magnetometry was used to compare annealed and non-annealed samples, with an increase in ferromagnetic moment observed on annealing of the pure $\mathrm{NiO}$ sample and indeed the pure $\mathrm{CeO}_{2}$ sample. The $5 \% \mathrm{Ni}-\mathrm{CeO}_{2}$ sample demonstrated a decrease on annealing, perhaps due to the drop-off of ferromagnetism in Ni-CeO2 samples with nickel doping levels of above $4 \%$.

Magnetic ceria are important in several applications from magnetic data storage devices to magnetically recoverable catalysts, and weak room temperature ferromagnetism induced by transition metal doping is a facile method to realise the aforementioned applications at the nanoscale.

\section{Acknowledgments}

C.W.D. and J.C.B. thank the Ramsay trust for past and current Ramsay Fellowships. John Warren (School of Materials, University of Manchester) is thanked for his generous help with XRD. James McGettrick, Tristan Watson (SPECIFIC), Danny Ovens and Jonathan Counsell (Kratos Analytical Ltd.) are thanked for XPS measurements. Andreas Kafizas (Imperial College London) is thanked for his help in interpretation of UV-Visible spectra.

\section{Author Contributions}

J.C.B. performed the experimental work and wrote the bulk of the manuscript. P.O.B. and P.D.M. provided TEM, UV/Visible and XRD characterization, P.S. performed SQUID measurements and wrote the magnetism section and C.W.D. supervised the work and conceived the idea.

\section{Conflicts of Interest}

The authors declare no conflict of interest.

\section{References}

1. Ozin, G.A.; Arsenault, A.; Cademartiri, L. Nanochemistry: A Chemical Approach to Nanomaterials; 2nd ed.; Royal Society of Chemistry: London, UK, 2008.

2. Patzke, G.R.; Zhou, Y.; Kontic, R.; Conrad, F. Oxide nanomaterials: Synthetic developments, mechanistic studies, and technological innovations. Angew. Chem. Int. Ed. 2011, 50, 826-859.

3. Bear, J.; Charron, G.; Fernández-Argüelles, M.T.; Massadeh, S.; McNaughter, P.; Nann, T. In Vivo Applications of Inorganic Nanoparticles. In BetaSys: Systems Biology of Regulated Exocytosis in Pancreatic $\beta$-Cells; Systems Biology Series; Springer: New York, NY, USA, 2011; Volume 2, pp. 185-220. 
4. Franke, M.E.; Koplin, T.J.; Simon, U. Metal and metal oxide nanoparticles in chemiresistors: Does the nanoscale matter? Small 2006, 2, 36-50.

5. Chen, X.; Mao, S.S. Titanium Dioxide Nanomaterials: Synthesis, Properties, Modifications, and Applications. Chem. Rev. 2007, 107, 2891-2959.

6. Zoolfakar, A.S.; Rani, R.A.; Morfa, A.J.; O’Mullane, A.P.; Kalantar-zadeh, K. Nanostructured copper oxide semiconductors: A perspective on materials, synthesis methods and applications. J. Mater. Chem. C 2014, 2, 5247-5270.

7. Hu, Y.H. A Highly Efficient Photocatalyst-Hydrogenated $\mathrm{Black}^{\mathrm{TiO}} 2$ for the Photocatalytic Splitting of Water. Angew. Chem. Int. Ed. 2012, 51, 12410-12412.

8. Ni, M.; Leung, M.K.H.; Leung, D.Y.C.; Sumathy, K. A review and recent developments in photocatalytic water-splitting using for hydrogen production. Renew. Sustain. Energy Rev. 2007, $11,401-425$.

9. Scanlon, D.O.; Dunnill, C.W.; Buckeridge, J.; Shevlin, S.A.; Logsdail, A.J.; Woodley, S.M.; Catlow, C.R.A.; Powell, M.J.; Palgrave, R.G.; Parkin, I.P.; et al. Band alignment of rutile and anatase $\mathrm{TiO}_{2}$. Nat. Mater. 2013, 12, 798-801.

10. Li, S.-Y.; Niklasson, G.A.; Granqvist, C.G. Nanothermochromics with $\mathrm{VO}_{2}$-based core-shell structures: Calculated luminous and solar optical properties. J. Appl. Phys. 2011, 109, 113515.

11. Chen, Z.; Gao, Y.; Kang, L.; Cao, C.; Chen, S.; Luo, H. Fine crystalline $\mathrm{VO}_{2}$ nanoparticles: Synthesis, abnormal phase transition temperatures and excellent optical properties of a derived $\mathrm{VO}_{2}$ nanocomposite foil. J. Mater. Chem. A 2014, 2, 2718-2727.

12. Son, J.-H.; Wei, J.; Cobden, D.; Cao, G.; Xia, Y. Hydrothermal Synthesis of Monoclinic $\mathrm{VO}_{2}$ Micro- and Nanocrystals in One Step and Their Use in Fabricating Inverse Opals. Chem. Mater. 2010, 22, 3043-3050.

13. Zhao, Y.; Dunnill, C.W.; Zhu, Y.; Gregory, D.H.; Kockenberger, W.; Li, Y.; Hu, W.; Ahmad, I.; McCartney, D.G. Low-Temperature Magnetic Properties of Hematite Nanorods. Chem. Mater. 2007, 19, 916-921.

14. Peveler, W.J.; Bear, J.C.; Southern, P.; Parkin, I.P. Organic-inorganic hybrid materials: Nanoparticle containing organogels with myriad applications. Chem. Commun. 2014, 50, 14418-14420.

15. Crick, C.R.; Bear, J.C.; Southern, P.; Parkin, I.P. A general method for the incorporation of nanoparticles into superhydrophobic films by aerosol assisted chemical vapour deposition. J. Mater. Chem. A 2013, 1, 4336-4344.

16. Bear, J.C.; Yu, B.; Blanco-Andujar, C.; McNaughter, P.D.; Southern, P.; Mafina, M.-K.; Pankhurst, Q.A.; Parkin, I.P. A low cost synthesis method for functionalised iron oxide nanoparticles for magnetic hyperthermia from readily available materials. Faraday Discuss. 2014, 175, 83-95.

17. Jordan, A.; Scholz, R.; Wust, P.; Fähling, H.; Felix, R. Magnetic fluid hyperthermia (MFH): Cancer treatment with AC magnetic field induced excitation of biocompatible superparamagnetic nanoparticles. J. Magn. Magn. Mater. 1999, 201, 413-419.

18. Dobson, J. Magnetic nanoparticles for drug delivery. Drug Dev. Res. 2006, 67, 55-60.

19. Dunnill, C.W.; Ansari, Z.; Kafizas, A.; Perni, S.; Morgan, D.J.; Wilson, M.; Parkin, I.P. Visible light photocatalysts - N-doped $\mathrm{TiO}_{2}$ by sol-gel, enhanced with surface bound silver nanoparticle islands. J. Mater. Chem. 2011, 21, 11854-11861. 
20. Dunnill, C.W.; Parkin, I.P. Nitrogen-doped $\mathrm{TiO}_{2}$ thin films: Photocatalytic applications for healthcare environments. Dalton Trans. 2011, 40, 1635-1640.

21. Na, H.; Song, I.; Hyeon, T. Inorganic Nanoparticles for MRI Contrast Agents. Adv. Mater. 2009, 21, 2133-2148.

22. Bridot, J.; Dayde, D.; Riviere, C.; Mandon, C.; Billotey, C.; Lerondel, S. Hybrid gadolinium oxide nanoparticles combining imaging and therapy. J. Mater. Chem. 2009, 19, 2328-2335.

23. Na, H.B.; Lee, J.H.; An, K.; Park, Y.I.; Park, M.; Lee, I.S.; Nam, D.-H.; Kim, S.T.; Kim, S.-H.; Kim, S.-W.; et al. Development of a $\mathrm{T}_{1}$ Contrast Agent for Magnetic Resonance Imaging Using MnO Nanoparticles. Angew. Chem. Int. Ed. 2007, 46, 5397-5401.

24. Cornell, R.M.; Schwertmann, U. The Iron Oxides: Structure, Properties, Reactions, Occurrences and Uses; Wiley: Hoboken, NJ, USA, 2006.

25. Terris, B.D.; Thomson, T. Nanofabricated and self-assembled magnetic structures as data storage media. J. Phys. Appl. Phys. 2005, 38, R199-R222.

26. Reiss, G.; Hütten, A. Magnetic nanoparticles: Applications beyond data storage. Nat. Mater. 2005, 4, 725-726.

27. Chng, L.L.; Erathodiyil, N.; Ying, J.Y. Nanostructured Catalysts for Organic Transformations. Acc. Chem. Res. 2013, 46, 1825-1837.

28. Crick, C.R.; Bear, J.C.; Kafizas, A.; Parkin, I.P. Superhydrophobic Photocatalytic Surfaces through Direct Incorporation of Titania Nanoparticles into a Polymer Matrix by Aerosol Assisted Chemical Vapor Deposition. Adv. Mater. 2012, 24, 3505-3508.

29. Xu, L.; Karunakaran, R.G.; Guo, J.; Yang, S. Transparent, Superhydrophobic Surfaces from One-Step Spin Coating of Hydrophobic Nanoparticles. ACS Appl. Mater. Interfaces 2012, 4, 1118-1125.

30. Bhatta, U.M.; Ross, I.M.; Saghi, Z.; Stringfellow, A.; Sayle, D.; Sayle, T.X.T.; Karakoti, A.; Reid, D.; Seal, S.; Möbus, G. Atomic motion on various surfaces of ceria nanoparticles in comparison. J. Phys. Conf. Ser. 2012, 371, doi:10.1088/1742-6596/371/1/012007.

31. Chattopadhyay, J.; Son, J.E.; Pak, D. Preparation and characterizations of Ni-alumina, Ni-ceria and $\mathrm{Ni}$-alumina/ceria catalysts and their performance in biomass pyrolysis. Korean J. Chem. Eng. 2011, $28,1677-1683$.

32. Zhang, S.; Muratsugu, S.; Ishiguro, N.; Tada, M. Ceria-Doped Ni/SBA-16 Catalysts for Dry Reforming of Methane. ACS Catal. 2013, 3, 1855-1864.

33. Pino, L.; Vita, A.; Cipitì, F.; Laganà, M.; Recupero, V. Hydrogen production by methane tri-reforming process over Ni-ceria catalysts: Effect of La-doping. Appl. Catal. B Environ. 2011, 104, 64-73.

34. Xu, J.; Xue, B.; Liu, Y.-M.; Li, Y.-X.; Cao, Y.; Fan, K.-N. Mesostructured Ni-doped ceria as an efficient catalyst for styrene synthesis by oxidative dehydrogenation of ethylbenzene. Appl. Catal. Gen. 2011, 405, 142-148.

35. Qureshi, U.; Dunnill, C.W.; Parkin, I.P. Nanoparticulate cerium dioxide and cerium dioxide-titanium dioxide composite thin films on glass by aerosol assisted chemical vapour deposition. Appl. Surf. Sci. 2009, 256, 852-856.

36. Gomez, V.; Clemente, A.; Irusta, S.; Balas, F.; Santamaria, J. Identification of $\mathrm{TiO}_{2}$ nanoparticles using $\mathrm{La}$ and $\mathrm{Ce}$ as labels: Application to the evaluation of surface contamination during the handling of nanosized matter. Environ. Sci. Nano 2014, 1, 496-503. 
37. Naganuma, T.; Traversa, E. Stability of the $\mathrm{Ce}^{3+}$ valence state in cerium oxide nanoparticle layers. Nanoscale 2012, 4, 4950-4953.

38. Trovarelli, A. Catalytic Properties of Ceria and $\mathrm{CeO}_{2}-$ Containing Materials. Catal. Rev. 1996, 38, 439-520.

39. Tao, Z.; Hou, G.; Xu, N.; Zhang, Q. A highly coking-resistant solid oxide fuel cell with a nickel doped ceria: $\mathrm{Ce}_{1-x} \mathrm{Ni}_{x} \mathrm{O}_{2-y}$ reformation layer. Int. J. Hydrog. Energy 2014, 39, 5113-5120.

40. Sun, C.; Li, H.; Chen, L. Nanostructured ceria-based materials: Synthesis, properties, and applications. Energy Environ. Sci. 2012, 5, 8475-8505.

41. Dohčević-Mitrović, Z.D.; Paunović, N.; Radović, M.; Popović, Z.V.; Matović, B.; Cekić, B.; Ivanovski, V. Valence state dependent room-temperature ferromagnetism in Fe-doped ceria nanocrystals. Appl. Phys. Lett. 2010, 96, 203104.

42. Thurber, A.; Reddy, K.M.; Shutthanandan, V.; Engelhard, M.H.; Wang, C.; Hays, J.; Punnoose, A. Ferromagnetism in chemically synthesized $\mathrm{CeO}_{2}$ nanoparticles by Ni doping. Phys. Rev. B 2007, 76, 165206.

43. Xia, C.; Hu, C.; Chen, P.; Wan, B.; He, X.; Tian, Y. Magnetic properties and photoabsorption of the $\mathrm{Mn}$-doped $\mathrm{CeO}_{2}$ nanorods. Mater. Res. Bull. 2010, 45, 794-798.

44. Brito, P.C.A.; Santos, D.A.A.; Duque, J.G.S.; Macêdo, M.A. Structural and magnetic study of Fe-doped $\mathrm{CeO}_{2}$. Phys. B Condens. Matter 2010, 405, 1821-1825.

45. Ferrari, V.; Llois, A.M.; Vildosola, V. Co-doped ceria: Tendency towards ferromagnetism driven by oxygen vacancies. J. Phys. Condens. Matter 2010, 22, doi:10.1088/0953-8984/22/27/276002.

46. Thurber, A.; Reddy, K.M. High-temperature magnetic-field-induced activation of room-temperature ferromagnetism in $\mathrm{Ce}_{1-x} \mathrm{Ni}_{x} \mathrm{O}_{2}$. J. Appl. Phys. 2007, 101, 09N506.

47. Fernandes, V.; Mossanek, R.J.O.; Schio, P.; Klein, J.J.; de Oliveira, A.J.A.; Ortiz, W.A.; Mattoso, N.; Varalda, J.; Schreiner, W.H.; Abbate, M.; et al. Dilute-defect magnetism: Origin of magnetism in nanocrystalline $\mathrm{CeO}_{2}$. Phys. Rev. B 2009, 80, doi: 10.1103/PhysRevB.80.035202.

48. Chen, S.-Y.; Fong, K.-W.; Peng, T.-T.; Dong, C.-L.; Gloter, A.; Yan, D.-C.; Chen, C.-L.; Lin, H.-J.; Chen, C.-T. Enhancement of Ferromagnetism in $\mathrm{CeO}_{2}$ Nanoparticles by Nonmagnetic $\mathrm{Cr}^{3+}$ Doping. J. Phys. Chem. C 2012, 116, 26570-26576.

49. Sundaresan, A.; Bhargavi, R.; Rangarajan, N.; Siddesh, U.; Rao, C.N.R. Ferromagnetism as a universal feature of nanoparticles of the otherwise nonmagnetic oxides. Phys. Rev. B 2006, 74, doi: 10.1103/PhysRevB.74.161306.

50. Ranjith, K.S.; Saravanan, P.; Chen, S.-H.; Dong, C.-L.; Chen, C.L.; Chen, S.-Y.; Asokan, K.; Rajendra Kumar, R.T. Enhanced Room-Temperature Ferromagnetism on Co-Doped $\mathrm{CeO}_{2}$ Nanoparticles: Mechanism and Electronic and Optical Properties. J. Phys. Chem. C 2014, 118, 27039-27047.

51. Wang, Z.; Quan, Z.; Lin, J. Remarkable Changes in the Optical Properties of $\mathrm{CeO}_{2}$ Nanocrystals Induced by Lanthanide Ions Doping. Inorg. Chem. 2007, 46, 5237-5242.

52. Kumar, A.; Babu, S.; Karakoti, A.S.; Schulte, A.; Seal, S. Luminescence Properties of Europium-Doped Cerium Oxide Nanoparticles: Role of Vacancy and Oxidation States. Langmuir 2009, 25, 10998-11007. 
53. Chen, X.; Li, G.; Su, Y.; Qiu, X.; Li, L.; Zou, Z. Synthesis and room-temperature ferromagnetism of $\mathrm{CeO}_{2}$ nanocrystals with nonmagnetic $\mathrm{Ca}^{2+}$ doping. Nanotechnology 2009, 20, doi:10.1088/ 0957-4484/20/11/115606.

54. NIST X-ray Photoelectron Spectroscopy (XPS) Database, Version 3.5. Available online: http://srdata.nist.gov/xps/ (accessed on 23 February 2015).

55. Burroughs, P.; Hamnett, A.; Orchard, A.F.; Thornton, G. Satellite structure in the X-ray photoelectron spectra of some binary and mixed oxides of lanthanum and cerium. J. Chem. Soc. Dalton Trans. 1976, 1686-1698.

56. Mullins, D.R.; Overbury, S.H.; Huntley, D.R. Electron spectroscopy of single crystal and polycrystalline cerium oxide surfaces. Surf. Sci. 1998, 409, 307-319.

57. Moulder, J.F.; Stickle, W.F.; Sobol, P.E.; Bomben, K.D. Handbook of X-ray Photoelectron Spectroscopy: A Reference Book of Standard Spectra for Identification and Interpretation of Xps Data; Physical Electronics: Eden Prairie, MN, USA, 1995; pp. 142-143.

58. Taguchi, M.; Takami, S.; Adschiri, T.; Nakane, T.; Sato, K.; Naka, T. Supercritical hydrothermal synthesis of hydrophilic polymer-modified water-dispersible $\mathrm{CeO}_{2}$ nanoparticles. CrystEngComm 2011, 13, 2841-2848.

59. Zhang, F.; Chan, S.-W.; Spanier, J.E.; Apak, E.; Jin, Q.; Robinson, R.D.; Herman, I.P. Cerium oxide nanoparticles: Size-selective formation and structure analysis. Appl. Phys. Lett. 2002, 80, 127-129.

60. Zhou, X.D.; Huebner, W. Size-induced lattice relaxation in $\mathrm{CeO}_{2}$ nanoparticles. Appl. Phys. Lett. 2001, 79, 3512-3514.

61. Mogensen, M.; Sammes, N.M.; Tompsett, G.A. Physical, chemical and electrochemical properties of pure and doped ceria. Solid State Ion. 2000, 129, 63-94.

62. Griffiths, T.R.; Davies, M.J.; Hubbard, H.V.S.A. Spectroscopic studies on single crystals having the fluorite lattice. Part 1-The fundamental absorption edge; Urbach's rule and the Debye temperature in $\mathrm{CeO}_{2}$. J. Chem. Soc. Faraday Trans. 2 Mol. Chem. Phys. 1976, 72, 765-772.

63. Park, J.; An, K.; Hwang, Y.; Park, J.-G.; Noh, H.-J.; Kim, J.-Y.; Park, J.-H.; Hwang, N.-M.; Hyeon, T. Ultra-large-scale syntheses of monodisperse nanocrystals. Nat. Mater. 2004, 3, 891-895.

(C) 2015 by the authors; licensee MDPI, Basel, Switzerland. This article is an open access article distributed under the terms and conditions of the Creative Commons Attribution license (http://creativecommons.org/licenses/by/4.0/). 